\title{
Role of Cyproheptadine in Various Psychiatric Conditions
}

\author{
Aritra Chakraborty
}

\begin{abstract}
Though cyproheptadine is commonly used for treatment of different allergic conditions, the molecule is effective in different psychiatric conditions mainly due to antiserotonin property. Cyproheptadine can be used in different psychiatric conditions like functional gastrointestinal disorders, serotonin syndrome, akathisia, tardive dyskinesia, anorexia nervosa, stimulant-induced weight loss, antidepressant induced sexual dysfunction, neuropsychiatric adverse effects associated with efavirenz therapy in HIV positive patients, migraine type headache, augmentation agent in schizophrenia. As the molecule is not very costly, its use can help in improving psychiatric practice in developing nations.

Keywords: Antidepressants, Improving psychiatric practice, Schizophrenia.

Indian Journal of Private Psychiatry (2019): 10.5005/jp-journals-10067-0034
\end{abstract}

\section{INTRODUCTION}

Cyproheptadine belongs to the first generation piperidine-a subgroup of the first generation antihistamine. Cyproheptadine is commonly used for the treatment of different allergic conditions. However, it was found to be effective in the treatment of some psychiatric conditions also., ${ }^{1,2}$

Along with the antihistamine property cyproheptadine has antiserotonin property by antagonizing action on $5-\mathrm{HT}_{2}$ receptor. It also has anticholinergic, antidopaminergic, and antiandrogenic property. $^{3}$

\section{Cyproheptadine in Childhood Functional Gastrointestinal Disorders}

Functional dyspepsia is characterized by increased gastric sensitivity to distension. Gastric (mainly fundic area) contraction and relaxation are regulated by $5-\mathrm{HT}_{2}$ receptors. So, cyproheptadine with its $5-\mathrm{HT}_{2 \mathrm{~A}}$ antagonistic property is effective in these cases. ${ }^{4}$

Nociceptive stimulation of $5-\mathrm{HT}_{1 \mathrm{~B}}, 5-\mathrm{HT}_{2 \mathrm{~A}}$, and $5-\mathrm{HT}_{6}$ receptors in excessive manner is implicated in functional abdominal pain. $5-\mathrm{HT}_{2 \mathrm{~A}}$ antagonism and calcium channel blocking property in intestinal muscles are implicated in the use of cyproheptadine in functional abdominal pain. ${ }^{5}$

$5 \mathrm{HT}$ level is found to be increased in diarrhea predominant irritable bowel syndrome. Therefore, cyproheptadine with its antiserotonin property is useful in the treatment of irritable bowel syndrome. ${ }^{5,6}$

Cyproheptadine is effective in the treatment of abdominal migraine, cyclical vomiting of children also., ${ }^{7,8}$

\section{Cyproheptadine in Serotonin Syndrome}

Serotonin syndrome is a life threatening condition due to increased serotonergic activity in the central nervous system (CNS) and characterized by altered mental status, autonomic dysfunction, and abnormalities of neuromuscular function. Serotonergic drugs like selective serotonin reuptake inhibitors (SSRIs) when used in combination, in high doses or in sensitive individuals can cause serotonin syndrome by increased neurotransmission in CNS by stimulation of the postsynaptic $5-\mathrm{HT}_{1 \mathrm{~A}}$ and $5-\mathrm{HT}_{2 \mathrm{~A}}$ receptors. ${ }^{3}$

Cyproheptadine can be used as an antidote for serotonin syndrome because of the antagonistic action on $5-\mathrm{HT}_{2 \mathrm{~A}}$ receptor.
Department of Psychiatry, Bankura Sammilani Medical College, Bankura, West Bengal, India

Corresponding Author: Aritra Chakraborty, Department of Psychiatry, Bankura Sammilani Medical College, Bankura, West Bengal, India, Phone: +91 9474735129, e-mail: dr.aritra.chakraborty@gmail.com

How to cite this article: Chakraborty A. Role of Cyproheptadine in Various Psychiatric Conditions. Ind J Priv Psychiatry 2019;13(2):58-61.

Source of support: Nil

Conflict of interest: None

An initial dose of $12 \mathrm{mg}$ of cyproheptadine is recommended, followed by 2 mg every 2 hours until clinical response is seen. Maintenance dose of $8 \mathrm{mg}$ of cyproheptadine six hourly is recommended. ${ }^{9-11}$ Several case reports have shown that cyproheptadine is effective in mild to moderate cases of serotonin syndrome, but its efficacy in severe cases has not been studied properly.

\section{Cyproheptadine in Anorexia Nervosa}

Cyproheptadine has $\mathrm{H}_{1}$ antihistaminic action and it also promotes growth hormone secretion. Due to these actions, it is used to increase appetite and help in gaining weight. Cyproheptadine is effective in treating anorexia nervosa. Probably nonbulimic type of anorexia nervosa patients responds better to cyproheptadine. ${ }^{12,13}$

\section{Cyproheptadine in Stimulant-induced Weight Loss, Anorexia and Insomnia}

Children and adolescents with attention deficit hyperactivity disorder often develop the problem of anorexia, weight loss, and insomnia on using the stimulants, which may lead to poor compliance to the treatment. Cyproheptadine has been shown to promote weight gain and it also improves sleep quality. Commonly night time dose of 4-8 mg of cyproheptadine is used. ${ }^{14}$

\section{Cyproheptadine in Antidepressant- induced Sexual Dysfunction}

Sexual dysfunction is a known side effect of antidepressants. Nowadays, sexual dysfunctions are often reported by the patients

(c) The Author(s). 2019 Open Access This article is distributed under the terms of the Creative Commons Attribution 4.0 International License (https://creativecommons. org/licenses/by-nc/4.0/), which permits unrestricted use, distribution, and non-commercial reproduction in any medium, provided you give appropriate credit to the original author(s) and the source, provide a link to the Creative Commons license, and indicate if changes were made. The Creative Commons Public Domain Dedication waiver (http://creativecommons.org/publicdomain/zero/1.0/) applies to the data made available in this article, unless otherwise stated. 
taking antidepressants probably because of the expanded indications for antidepressants, increase in the number of antidepressant prescription, greater emphasis on the biological model of depression, increased willingness to discuss sexual problems, increased awareness of the adverse effects of drugs, etc.

Selective SSRIs are commonly used antidepressants nowadays. Though they are excellent antidepressants, they too have some important adverse effects like sexual dysfunction which can lead to compliance problems.

Probably the serotonergic property, effect on a1 antiadrenergic receptor, indirect inhibitory effect on dopamine are the causes responsible for sexual dysfunction like anorgasmia, delayed ejaculation, decreased libido, and erectile dysfunction. ${ }^{15}$ Serotonin inhibits nitric oxide synthase (an enzyme involved in the pathway to achieve penile erection/lubrication) and this action is probably mediated by $5-\mathrm{HT}_{2}$ receptors.

Cyproheptadine has $5-\mathrm{HT}_{2}$ antagonist actions and so it improves sexual function. Cyproheptadine (4-12 mg/day) can be used 1-2 hours before the sexual activity or daily basis. ${ }^{16}$

\section{Cyproheptadine in the Treatment of Akathisia}

According to DSM-IV-TR, akathisia is characterized by a subjective feeling of restlessness and by objectively observed typical movements such as shuffling of the legs, pacing, rocking from foot to foot, or the inability to sit down or stand still (American Psychiatry Association, 2000). Akathisia can be of different types depending on the time of onset-acute, chronic or tardive akathisia.

Not only the first generation but also atypical antipsychotics can cause akathisia. The prevalence of akathisia in patients with schizophrenia varies and is in-between $5 \%$ and $37 \%$. Other psychotropic medications like SSRI, monoamine oxidase inhibitor, and tricyclic antidepressants have been found to be associated with akathisia. Not only in patients with schizophrenia or mood disorders, but akathisia may also be seen in a wide range of other conditions like Parkinsonian syndromes and traumatic brain injury patients.

The exact pathophysiology underlying akathisia is not known properly. It is thought that basal ganglia and striatal circuitry dysfunction are probably responsible for developing akathisia and the key neurotransmitters are gamma-aminobutyric acid (GABA), serotonin and dopamine. Dopaminergic motor function in nigrostriatal pathway is modulated by GABA and serotonin. An imbalance between dopaminergic and serotonergic neurotransmitter system is implicated in the development of akathisia.

Drugs with $5-\mathrm{HT}_{2 \mathrm{~A}}$ antagonistic property can be helpful in the treatment of akathisia. Cyproheptadine (8-16 mg/day) can be used to treat antipsychotic induced akathisia due to its $5-\mathrm{HT}_{2 \mathrm{~A}}$ antagonistic property. This mechanism is probably by counteracting antipsychotic induced dopamine $D_{2}$ receptor blockade resulting in enhanced dopamine neurotransmission. In one study, cyproheptadine was found to be equally effective compared with propranolol in the treatment of akathisia. ${ }^{17}$

\section{Cyproheptadine in Tardive Dyskinesia}

Tardive dyskinesia is a type of abnormal, involuntary movement disorder usually involving face and sometimes limbs, which emerges as one of the adverse effects of antipsychotic drugs, especially the typical ones. The risk of tardive dyskinesia increases with higher doses and longer durations of treatment. In some case reports, cyproheptadine was found to be effective in the treatment of tardive dyskinesia. ${ }^{18}$

\section{Cyproheptadine in Nightmares of Patients with Posttraumatic Stress Disorder}

Cyproheptadine is effective in reducing nightmares of patients with post traumatic stress disorder. Moreover, the sedative property of cyproheptadine makes it a good choice for such patients.

Cyproheptadine can improve sleep architecture and REM sleep pattern. Cyproheptadine causes rapid eye movement (REM) suppression due to its antagonistic effect on serotonin autoreceptor $\left(5-\mathrm{HT}_{1 \mathrm{~A}}\right)$, which results in increased serotonin outflow at the midbrain raphe. The anticholinergic property of cyproheptadine is also responsible for the reduction of REM sleep. Commonly used dose of cyproheptadine in such cases is $4-24 \mathrm{mg} /$ day. ${ }^{19-23}$ However, a few studies have shown conflicting results too.

\section{Cyproheptadine in HiV Positive Patients for Neuropsychiatric Adverse Effects of Efavirenz}

Efavirenz belongs to non-nucleoside reverse transcriptase inhibitors (NNRTIs) group of antiretroviral drug, used in the treatment of HIV infection. Neuropsychiatric adverse reactions are common following efavirenz therapy (up to 50\%) and more common within the first 2 weeks of treatment. These adverse effects can lead to poor compliance to treatment. Dizziness, headache, nightmares, sleep disturbance, concentration difficulty, mild cognitive impairment, anxiety disorders, depressive disorders, mania, emotional lability, poor impulse control, hallucination, delusion, aggressive behavior, and catatonia are the most commonly reported adverse reactions. The neuropsychiatric effects of efavirenz appear to be dosedependent and mediated by the $5-\mathrm{HT}_{2 \mathrm{~A}}$ receptor.

Cyproheptadine helps in improving these adverse effects. Moreover, some of the adverse effects of cyproheptadine such as increased appetite and weight gain are beneficial for HIV patients with weight loss and poor appetite. ${ }^{24-27}$

\section{Cyproheptadine as Augmentation Agent in SCHIZOPHRENIA}

Typical antipsychotics block mainly $\mathrm{D}_{2}$ receptors. 5-HT receptor plays an important role in the negative symptoms of schizophrenia. Atypical antipsychotics act better than typical antipsychotics in the treatment of negative symptoms due to their action on 5-HT receptors.

Clozapine exhibits higher serotonin $\left(5-\mathrm{HT}_{2}\right)$ than dopamine $\left(D_{2}\right)$ blockade in vivo, which contributes to clozapine's greater efficacy and lower propensity for extrapyramidal adverse effects. High $5-\mathrm{HT}_{2}$ blockade and moderate $\mathrm{D}_{2}$ blockade can also be obtained by combining two medications: one with prominent $5-\mathrm{HT}_{2}$ antagonism (in sufficient amount) and another with $\mathrm{D}_{2}$ antagonism (in less amount). One such optimum combination can be made by combining cyproheptadine (4-6 mg three times daily (TDS)) with a low dose of a typical antipsychotic ( $D_{2}$ antagonist).

Therefore, it can be said that cyproheptadine, due to 5-HT antagonistic action, can be used as an augmentation agent in treating chronic schizophrenia patients to reduce extrapyramidal 
adverse effects of conventional antipsychotics such as haloperidol and to counteract the negative symptoms. ${ }^{28-30}$

\section{Cyproheptadine in Treatment of Migraine Type Headache}

Trigeminal-vascular system plays an important role in the pathogenesis of migraine. Release of serotonin from platelets results in vasoconstriction (serotonin $1 \mathrm{~B}$ and $1 \mathrm{D}$ receptors are implicated) and resulting in decreased cerebral blood flow. This is followed by the depletion of serotonin leading to cerebral vasodilatation and trigeminal nerve stimulation. These changes induce neurogenic inflammation and result in migraine headache.

Cyproheptadine inhibits the release of vasoactive peptides, including calcitonin gene-related peptides, with simultaneous inhibition of both serotonin 1B and 1D receptors and prevents neurogenic inflammation. Cyproheptadine in the dose of 4-8 $\mathrm{mg} /$ day can be used in migraine type headache in both children and adult population. ${ }^{31-33}$

\section{Conclusion}

Cyproheptadine has been found to be effective in many psychiatric conditions such as various functional gastrointestinal disorders, serotonin syndrome, akathisia, tardive dyskinesia, anorexia nervosa, stimulant induced weight loss, antidepressant-induced sexual dysfunction, neuropsychiatric adverse effects associated with efavirenz therapy in HIV positive patients, migraine type headache, and augmentation agent in schizophrenia. It is very interesting that a single molecule is effective in so many psychiatric conditions. There are so many drug treatment options for those conditions. However, most of them appear costly to poor patients. Cyproheptadine can be a cheaper treatment option for these conditions and so may be cost-effective in developing countries. But unfortunately the number of studies on cyproheptadine in such situations are limited. Therefore, the molecule should be studied for those conditions in different parts of the world to get a cheaper alternative treatment option.

\section{References}

1. Product Information: Periactin (R), cyproheptadine tablets and syrup prescribing information. West Point, PA: Merck \& Co.; 1999.

2. Pucci E, Petraglia F. Treatment of androgen excess in females: yesterday, today and tomorrow. Gynecol Endocrinol 1997;11(6):411433. DOI: 10.3109/09513599709152569.

3. Kapur S, Zipursky RB, Jones C, et al. Cyproheptadine: a potent in vivo serotonin antagonist. Am J Psychiatry 1997;154(6):884. DOI: 10.1176/ ajp.154.6.884a.

4. Takemura K, Takada K, Mameya S, et al. Regional and functional differences of 5-hydroxytryptamine-receptor subtypes in guinea pig stomach. Jpn J Pharmacol 1999;79(1):41-49. DOI: 10.1254/jjp.79.41.

5. Nascimento Jr EB, Seniuk JG, Godin AM, et al. Peripheral 5-HT1B and $5-\mathrm{HT} 2 \mathrm{~A}$ receptors mediate the nociceptive response induced by 5 -hydroxytryptamine in mice. Pharmacol Biochem Behav 2011;99(4):598-603. DOI: 10.1016/j.pbb.2011.06.016.

6. Rasquin A, Di Lorenzo C, Forbes D, et al. Childhood functional gastrointestinal disorders: child/adolescent. Gastroenterology 2006;130(5):1527-1537. DOI: 10.1053/j.gastro.2005.08.063.

7. Worawattanakul M, Rhoads JM, Lichtman SN, et al. Abdominal migraine: prophylactic treatment and follow-up. J Pediatr Gastroenterol Nutr 1999;28(1):37-40. DOI: 10.1097/00005176199901000-00010.
8. Rodriguez L, Diaz J, Nurko S. Safety and efficacy of cyproheptadine for treating dyspeptic symptoms in children.J Pediatr 2013;163(1):261267. DOI: 10.1016/j.jpeds.2012.12.096.

9. Boyer EW, Shannon M. The serotonin syndrome. N Engl J Med 2005;352(11):1112-1120. DOI: 10.1056/NEJMra041867. Errata in: N Engl J Med 2007;356(23):2437, N Engl J Med 2009;361(17):1714.

10. McDaniel WW. Serotonin syndrome: early management with cyproheptadine. Ann Pharmacother 2001;35(7-8):870-873. DOI: 10.1345/aph.10203.

11. Graudins A, Stearman A, Chan B. Treatment of the serotonin syndrome with cyproheptadine. J Emerg Med 1998;16(4):615-619. DOI: 10.1016/ S0736-4679(98)00057-2.

12. Halmi KA, Eckert E, LaDu TJ, et al. Anorexia nervosa: treatment efficacy of cyproheptadine and amitriptyline. Arch Gen Psychiatry 1986;43(2):177-181. DOI: 10.1001/archpsyc.1986.01800020087011.

13. Johnson C, Stuckey M, Mitchell J. Psychopharmacological treatment of anorexia nervosa and bulimia: review and synthesis. J Nerv Ment Dis 1983;171(9):524-534. DOI: 10.1097/00005053-198309000-00002.

14. Daviss WB, Scott J. A chart review of cyproheptadine for stimulantinduced weight loss. J Child Adolesc Psychopharmacol 2004;14(1): 65-73. DOI: 10.1089/104454604773840508.

15. Aizenberg D, Zemishlany Z, Weizman A. Cyproheptadine treatment of sexual dysfunction induced by serotonin reuptake inhibitors. Clin Neuropharmacol 1995;18(4):320-324. DOI: 10.1097/00002826199508000-00003.

16. Decastro RM. Reversal of MAOI-induced anorgasmia with cyproheptadine. Am J Psychiatry 1985;142(6):783. DOI: 10.1176/ ajp.142.6.783b.

17. Weiss $D$, Aizenberg $D$, Hermesh $\mathrm{H}$, et al. Cyproheptadine treatment in neuroleptic-induced akathisia. Br J Psychiatry 1995;167(4):483-486. DOI: 10.1192/bjp.167.4.483.

18. Gardos G, Cole JO. Pilot study of cyproheptadine (Periactin) in tardive dyskinesia [proceedings]. Psychopharmacol Bull 1978;14(2):18-20.

19. Friedman MJ. Drug treatment for PTSD. Answers and questions. Ann N Y Acad Sci 1997;821:359-371. DOI: 10.1111/j.1749-6632.1997.tb48292.x.

20. Harsch HH. Cyproheptadine for recurrent nightmares. Am J Psychiatry 1986;143(11):1491-1492. DOI: 10.1176/ajp.143.11.1491.

21. Brophy MH. Cyproheptadine for combat nightmares in post-traumatic stress disorder and dream anxiety disorder. Mil Med 1991;156(2):100101. DOI: $10.1093 / \mathrm{milmed} / 156.2 .100$.

22. Gupta S, Austin R, Cali LA, et al. Nightmares treated with cyproheptadine. J Am Acad Child Adolesc Psychiatry 1998;37(6): 570-572. DOI: 10.1097/00004583-199806000-00003.

23. Chokroverty S. An overview of sleep. In: Chokroverty S, ed., Sleep Disorders Medicine: Basic Science, Technical Considerations, and Clinical Aspects, 2nd ed., Boston: Butterworth-Heinemann; 1999. pp. 7-20.

24. Dabaghzadeh F, Khalili $H$, Ghaeli $P$, et al. Potential benefits of cyproheptadine in HIV-positive patients under treatment with antiretroviral drugs including efavirenz. Expert Opin Pharmacother 2012;13(18):2613-2624. DOI: 10.1517/14656566.2012.742887.

25. Dabaghzadeh F, Ghaeli $P$, Khalili $H$, et al. Cyproheptadine for prevention of neuropsychiatric adverse effects of efavirenz: a randomized clinical trial. AIDS Patient Care STDS 2013;27(3):146-154. DOI: 10.1089/apc.2012.0410.

26. Kenedi CA, Goforth HW. A systematic review of the psychiatric sideeffects of efavirenz. AIDS Behav 2011;15(8):1803-1818. DOI: 10.1007/ s10461-011-9939-5.

27. Marinho M, Novais C, Marques J, et al. Efavirenz and neuropsychiatric effects-when the treatment complicates matter further. Eur Psychiatry 2017;41(Suppl):S237. DOI: 10.1016/j.eurpsy.2017.01.2255.

28. Lee HS, Song DH, Kim JH, et al. Cyproheptadine augmentation of haloperidol in chronic schizophrenic patients: a double-blind placebo-controlled study. Int Clin Psychopharmacol 1995;10(2):67-72. DOI: 10.1097/00004850-199506000-00002.

29. Akhondzadeh S, Mohammadi MR, Amini-Nooshabadi H, et al. Cyproheptadine in treatment of chronic schizophrenia: a double- 
blind, placebo-controlled study. J Clin Pharm Ther 1999;24(1):49-52. DOI: 10.1046/j.1365-2710.1999.00197.x.

30. Chaudhry IB, Soni SD, Hellewell JS, et al. Effects of the 5HT antagonist cyproheptadineon neuropsychological function in chronic schizophrenia. Schizophr Res 2002;53(1-2):17-24. DOI: 10.1016/S0920-9964(01)00165-7.

31. Mathew NT. Pathophysiology, epidemiology, and impact of migraine. Clin Cornerstone 2001;4(3):1-17. DOI: 10.1016/S1098-3597(01)90035-3.
32. Siow HC, Pozo-Rosich P, Silberstein SD. Frovatriptan for the treatment of cluster headaches. Cephalalgia 2004;24(12):1045-1048. DOI: 10.1111/j.1468-2982.2004.00734.x.

33. Villalón CM, Olesen J. The role of CGRP in the pathophysiology of migraine and efficacy of CGRP receptor antagonists as acute antimigraine drugs. Pharmacol Ther 2009;124(3):309-323. DOI: 10.1016/j.pharmthera.2009.09.003. 